\title{
Transperitoneal Laparoscopic Pyeloplasty: Brazilian Initial Experience with 55 Cases
}

\author{
Marco T. C. Lasmar, Hilario A. Castro Junior, Alessandro Vengjer, Francisco A. T. Guerra, \\ Eugenio A. C. Souza, Lydston M. Rocha
}

Felicio Rocho Hospital, Belo Horizonte, Minas Gerais, Brazil

\begin{abstract}
Purpose: To evaluate prospectively the results obtained in 55 patients undergoing laparoscopic pyeloplasty through transperitoneal access.

Materials and Methods: From January 2005 to July 2009, fifty-five patients between 13 and 64 years old, were treated for ureteropelvic junction (UPJ) stenosis via a transperitoneal laparoscopy. All patients had clinical symptoms of high urinary obstruction and hydronephrosis confirmed by imaging methods. Anderson-Hynes dismembered pyeloplasty was performed in 51 patients and Fenger technique in the other 4 cases. Patients were clinically and imaging evaluated in the postoperative period at 3 and 6 months and then followed-up annually.

Results: The operative time ranged from 95 to $270 \mathrm{~min}$. The mean hospital stay was 2 days. The average blood loss was 170 $\mathrm{mL}$. The time to return to normal activities ranged from 10 to 28 days. Anomalous vessels were identified in 27 patients, intrinsic stenosis in 23 patients and 5 patients had high implantation of the ureter. Laparoscopic pyelolithotomy was successfully performed in 6 patients with associated renal stones. That series monitoring ranged from 1 to 55 months. One patient had longer urinary fistula (11 days), 3 patients had portal infection and 6 patients had prolonged ileus. There was one conversion due to technical difficulties. From the later postoperative complications, 2 patients had re-stenosis, one determined by Anderson-Hynes technique and the other by Fenger technique. The success rate was $95.65 \%$.

Conclusions: Laparoscopic pyeloplasty has functional results comparable to conventional open technique. It offers less morbidity, with aesthetic and post-operative convalescence benefits and lower complication rates.
\end{abstract}

Key words: kidney; ureter; laparoscopy; pyeloplasty; treatment outcome

Int Braz J Urol. 2010; 36: 678-84

\section{INTRODUCTION}

Ureteropelvic junction (UPJ) obstruction is one of the most common ureter intrinsic pathologies generally manifested by back pain, renal colic and urinary tract infection. It can lead to progressive hydronephrosis and renal dysfunction (1).

The gold standard treatment of this pathology is Anderson-Hynes dismembered pyeloplasty, tradi- tionally performed in a conventional open procedure, with success rates over $90 \%$ (2).

Minimally invasive techniques, both endoscopic and percutaneous, with incision of UPJ are also performed with low morbidity, but with success rates lower than those of conventional surgery $(3,4)$.

Laparoscopic pyeloplasty, first performed by Schuessler et al. (5), in 1993, maintains the principles of open dismembered pyeloplasty, with excellent 
functional results and significant reductions in morbidity (6).

The objective of the present a study was to evaluate prospectively, from the first visit to the follow-up after surgery, the results obtained in 55 patients undergoing laparoscopic pyeloplasty by transperitoneal access.

\section{MATERIALS AND METHODS}

In the period from January 2005 to July 2009 , 55 patients, 29 men and 26 women, aged between 13 and 64 years old were treated for UPJ stenosis through transperitoneal laparoscopy by the same surgeon (MTCL). All patients had clinical symptoms of high urinary obstruction and hydronephrosis, confirmed by intravenous urogram and / or multi-slice CT scan. None of them had undergone any previous treatment (Table-1).

Patients were placed in a lateral contralateral position on the side to be treated. Pneumoperitoneum was made with a Veress needle and maintained at 15 $\mathrm{mmHg}$. Three or four trocars were placed according to standard configuration (Figure-1), a paraumbilical one, another between this one and the ipsilateral iliac crest and the third between that and the xiphoid appendix. In 44 patients one more trocar was used being located in the anterior axillary line. A perito-
Table 1 - Summary of patient and surgical characteristics.

\begin{tabular}{ll}
\hline Number & \\
$\quad$ Male & 29 \\
$\quad$ Female & 26 \\
Age (years) & \\
$\quad$ Median & 36 \\
$\quad$ Range & $13-64$ \\
Technique & \\
$\quad$ Anderson-Hynes & 51 \\
$\quad$ Fenger & 4 \\
Number of ports per patient & \\
$\quad 3$ ports & 11 \\
$\quad 4$ ports & 44 \\
Side & \\
$\quad$ Right & 24 \\
$\quad$ Left & 31 \\
Renal calculus removed (patient) & $10.9 \%$ \\
\hline
\end{tabular}

neal incision was made in the line of Toldt and the colon was medially folded until identifying the ureter and renal pelvis. Anderson-Hynes dismembered pyeloplasty was performed in 51 patients and Fenger technique in the other 4 cases. In all cases was performed a suture of UPJ with 4-0 polyglycolic acid thread in separated stitches on the spatulated ureter

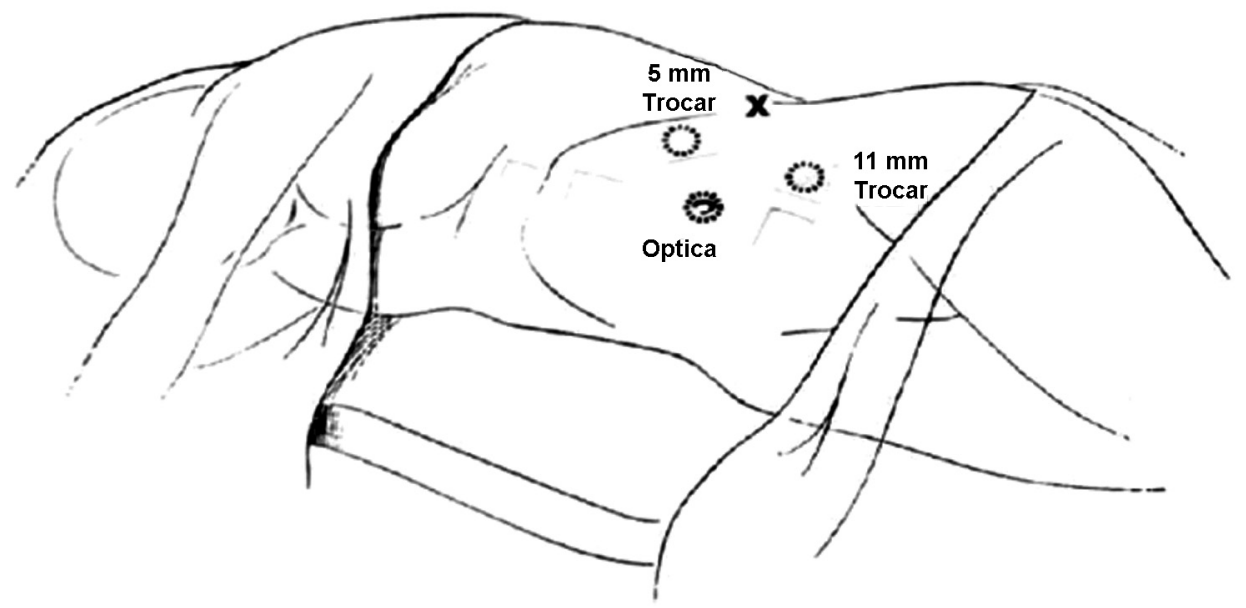

Figure 1 - Patient position for the procedure. 
and continuous stitches on renal pelvis. In 6 cases a lithiasis treatment was made previously identified in imaging studies, being the calculi successfully removed. The first 15 patients underwent implantation of double-J stent through retrograde way and in the others through anterograde way. They were removed after 6 weeks of surgery. All patients remained with intravesical Foley catheter for 24-48 h and Penrose drain for the same period, except when its drainage persisted. Patients were clinically assessed and imaging evaluated at 3 and 6 months and followed annually since then.

\section{RESULTS}

The operative and post-operative results are distributed in Table-2. Mean operative time was 150 minutes (ranging from 95 to $270 \mathrm{~min}$.). There was a progressive decrease in operative time after the first 20 cases. The average blood loss was $170 \mathrm{~mL}$ (60 to

Table 2 - Summary of results.

\begin{tabular}{lc}
\hline Technique & 51 \\
$\quad$ Anderson-Hynes & \\
$\quad$ Fenger & 4 \\
N. of ports/patient & \\
$\quad 3$ ports & 11 \\
$\quad 4$ ports & 44 \\
Operative time (min) & \\
$\quad$ Median & 150 \\
$\quad$ Range & $95-270$ \\
Conversion (\%) & 1.81 \\
Hospital stay (days) & \\
$\quad$ Median & 2 \\
$\quad$ Range & $1-11$ \\
Follow-up (months) & \\
$\quad$ Median & 22 \\
$\quad$ Range & $1-55$ \\
Return to normal activities (days) & \\
$\quad$ Median & 15 \\
$\quad$ Range & $10-28$ \\
Complications (\%) & 4.34 \\
Success rate (\%) & 95.65 \\
\hline
\end{tabular}

$370 \mathrm{~mL}$ ), measured by the content aspirated that may have contained urine. The mean hospital stay was 2 days ( 1 to 11 days). The average time to return to normal activities was 15 days (10 to 28 days).

Anderson-Hynes dismembered pyeloplasty was performed in 51 patients and Fenger plasty in 4. Anomalous vessels were identified in 27 patients $(49.09 \%)$, ureter intrinsic stenosis in 23 patients $(41.81 \%)$ and 5 patients $(9.09 \%)$ had ureter high implantation. Laparoscopic pyelolithotomy was successfully performed in 6 patients with associated calculi, with greater opening of the renal pelvis and using the laparoscopic equipment.

This series follow-up ranged from 1 to 55 months. Forty-six patients had more than 6 months of follow-up, with complete resolution of pain observed in 44 of these (95.65\%), except for two cases where re-stenosis was detected in postoperative follow-up period.

There was conversion to open surgery in a 13year-old patient due to technical difficulties, in a case carried out at the beginning of this series. One patient had urinary fistula, which lasted 11 days, 3 patients had portal infection and 6 patients had prolonged ileus. All these minor complications were treated conservatively with complete resolution. From the later postoperative complications, 2 patients $(4.35 \%)$, over six months of follow-up, showed re-stenosis, one in which the surgery was performed through Anderson-Hynes technique and the other through Fenger technique. These complications were identified at 8 and 4 months of follow-up respectively by low back pain after drinking water and was confirmed by imaging methods. The first was treated by retrograde endopyelotomy and the second by open pyeloplasty, both with success.

\section{COMMENTS}

Since its description in 1949 by AndersonHynes, open dismembered pyeloplasty has been the gold standard for UPJ obstruction treatment, with success rates exceeding $90 \%$ (2). The lumbar incision adopted most of the time (lumbotomy), among other factors, leads to higher morbidity in the procedure, mainly related to the use of analgesics postoperatively 
and worse cosmetic effect besides a longer period of convalescence (6).

Minimally invasive procedures have emerged with the aim of reducing the morbidity in the open surgery. Retrograde and anterograde endopyelotomy, pneumatic balloon dilatation, Acucise, cold Knife and more recently the use of laser were used for the purpose of treatment of UPJ stenosis. Such procedures have low morbidity, but lower rates of success $(3,4)$. Moreover, there is evidence that patients with large renal pelvis, poor kidney function and anomalous vessel are not good candidates for endoluminal techniques. Added to this, the long-term results are also worse, at around $63 \%$ with more frequent relapses (7).

Initially accepted with difficulty due to the long operative period and the need for advanced laparoscopic skills, video-assisted pyeloplasty decreased morbidity and improved cosmetic effect while maintaining success rates similar to those of the conventional open technique (1).

Anderson-Hynes dismembered technique is used in most series of published laparoscopic pyeloplasties, reflecting an attempt to reproduce the wellestablished principles of open surgery $(6,8)$, besides being more effective than other minimally invasive procedures $(3,4,7)$. The dismembered technique should always be considered, even in the presence of anomalous vessel, because in more than half of the cases there is an associated intrinsic stenosis (9).

Laparoscopic pyeloplasty can be performed by either trans or retroperitoneal approach. Although, the transperitoneal approach provides more working space for dissection and suturing with more defined anatomical references, retroperitoneoscopy promotes direct access to UPJ with less need for dissection and without violating the peritoneal envelope (10). Both operative time and the results of transperitoneal way are comparable to retroperitoneal access (11).

When evaluating the results based on the used ways, both the transperitoneal and retroperitoneal approaches offer similar success rates, with similar rates of complications (12-18), varying the choice according to surgeon's preference and experience.

There was a significant and progressive decrease in the operative time during this series, associated with greater experience acquired by the surgeon (MTCL), observing a final average time of $150 \mathrm{~min}$.
In the literature several series of video-laparoscopic pyeloplasty are described where there is evidence that the time varied from 77 to $312 \mathrm{~min}$ with progressive reduction in the postoperative period as it increases the number of cases, due to the learning curve (18). There was also a decrease in blood loss with the progression of the learning curve and therefore it was not necessary to perform blood transfusion in any patient.

Conversion was necessary in one patient in this series due to technical difficulties. The patient was 13 years old and was operated in the beginning of the presented series. The conversion rate was $1.81 \%$, consistent with other series described in the literature. $(17,18)$.

In this study there were two cases of re-stenosis (4.34\%), one performed through Fenger technique and the other through Anderson-Hynes. Reports of re-stenosis in the literature ranged from 3.5 to $4.8 \%$ of the cases with the use of Anderson-Hynes technique (18). We must consider that in open surgery the rates are similar and Fenger technique, itself, has higher rates of re-stenosis (2). Re-stenosis can be treated by laparoscopic approach, with success rates similar to those of primary obstruction (19). In our cases, re-stenosis was operated by open surgery because they occurred at the beginning of the surgeon's learning curve. Intraoperative complications are rare during laparoscopic pyeloplasty as well as postoperative complications, with rates ranging from $2 \%$ to $15 \%(18,20,21)$. Complications in this series were limited, totaling $10.9 \%$, which were a urinary fistula that lasted 11 days in one patient, three other patients who had operative wound infection and two cases of re-stenosis.

Open pyeloplasty has been the gold standard for the treatment of UPJ stenosis since its establishment, with long-term success rates higher than $90 \%$ (2). However, its morbidity is high especially related to chronic pain, risk of incisional hernia and later return to 'daily activities' (6). The success rates of laparoscopic pyeloplasty were comparable to those of open surgery with long-term rates as high as $98 \%$ (12-18).

In this series, there was a success rate of $95.65 \%$, consistent with the data presented in the literature for laparoscopic and open pyeloplasty Table-3. 


\begin{tabular}{|c|c|c|c|c|c|c|c|c|c|c|}
\hline 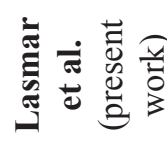 & $n$ & 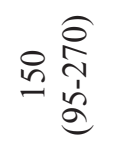 & $\sim \stackrel{\overparen{\Xi}}{\stackrel{\Xi}{\Xi}}$ & $\stackrel{\vec{\infty}}{-}$ & $\mapsto$ & 0 & $\stackrel{9}{0}$ & 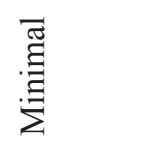 & 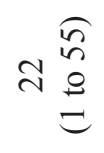 & $\begin{array}{l}n \\
\dot{b} \\
a\end{array}$ \\
\hline 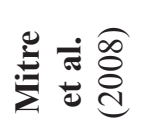 & F & î & 돌 & 0 & $\mapsto$ & 0 & 守. & 䄉 & $\underset{\sim}{\stackrel{\infty}{\stackrel{\infty}{d}}}$ & $\begin{array}{l}\dot{b} \\
\text { aे }\end{array}$ \\
\hline 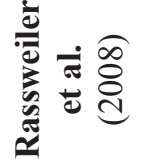 & $\stackrel{?}{ \pm}$ & 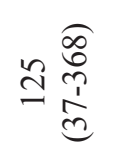 & $n \frac{\hat{\theta}}{\frac{1}{c}}$ & $\hat{o}$ & $\simeq$ & & ?̧: & $\overrightarrow{0} \cdot \frac{\pi}{0}$ & $n \frac{\sqrt{n}}{\frac{1}{d}}$ & $\stackrel{+}{+}$ \\
\hline 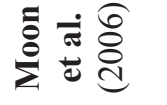 & $\stackrel{2}{I}$ & $\stackrel{\text { I }}{ \pm}$ & $m$ & $\begin{array}{l}0 \\
0\end{array}$ & $\stackrel{\underline{\mu}}{\hat{F}}$ & 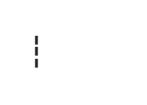 & $\vec{r}$ & ¿े & $\simeq$ & గֶః \\
\hline 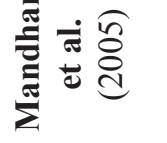 & ล & $\frac{n}{2}$ & $\nabla$ & $n$ & $\mapsto$ & 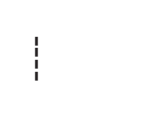 & $\stackrel{+}{\infty}$ & 艺 & $\simeq$ & 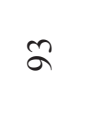 \\
\hline 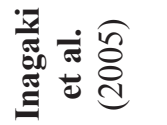 & 王 & 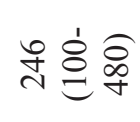 & 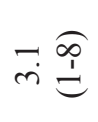 & 0 & $\mapsto$ & 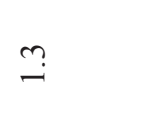 & $\underset{\infty}{\infty}$ & i & 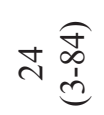 & $\approx$ \\
\hline 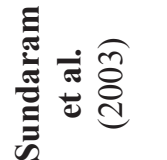 & ల & 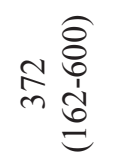 & $\hat{i}$ & $n$ & $\mapsto$ & $n$ & ป & 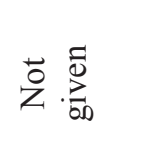 & 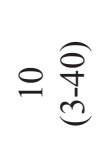 & ळ \\
\hline 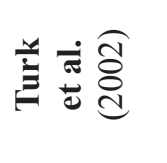 & gे & 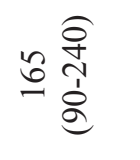 & ri & 0 & $H$ & ' & 0 & $\begin{array}{l}\frac{0}{0} \\
\frac{000}{60} \\
00 \\
0\end{array}$ & 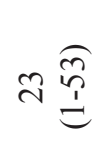 & $\stackrel{\hat{a}}{a}$ \\
\hline 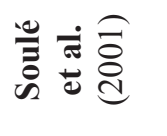 & $n$ & 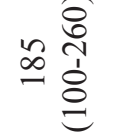 & $\stackrel{f}{\stackrel{f}{I}}$ & $\ddot{n}$ & $\simeq$ & ' & $\hat{\mathrm{I}}$ & 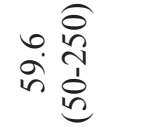 & 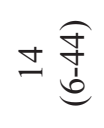 & $\frac{\mathfrak{\infty}}{\infty}$ \\
\hline 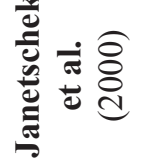 & $\hat{\sigma}$ & $=\frac{o}{a}$ & $F \stackrel{\overparen{i}}{d}$ & $\stackrel{\circ}{\mathrm{i}}$ & $\mapsto$ & ' & $\stackrel{n}{-}$ & 湆 & 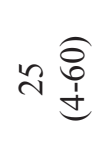 & बे \\
\hline & 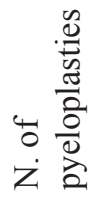 & 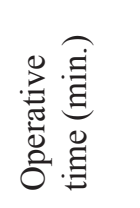 & 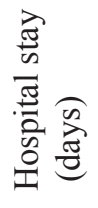 & 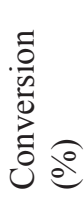 & 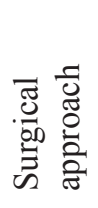 & 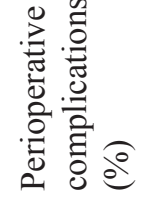 & 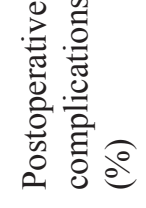 & 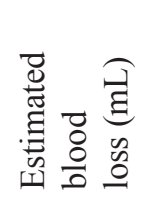 & 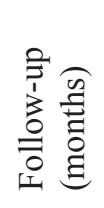 & 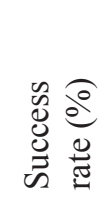 \\
\hline
\end{tabular}


Since its first report by Sung et al. (22), pyeloplasty has been performed also assisted by robotics, with results similar to laparoscopic procedures and standard open surgery. The most recent reports show a lower learning curve and shorter operative time, resulting mainly from a higher skill in surgery and simplification of suture (23), besides the opportunity to perform the treatment of bilateral pathology cases at once, with practicality, safety and without functional loss (24). The costs of robotic surgery are major limitations to the procedure application in several centers.

\section{CONCLUSIONS}

Laparoscopic pyeloplasty has functional results comparable to the conventional open technique and better than the other endoluminal procedures. It is a safe and effective alternative for the treatment of pyeloureteral junction stenosis and it can be considered as first choice by surgeons with experience in laparoscopy. The complication rates are low and concurrent procedures, as pyelolithotomies, can be performed.

\section{CONFLICT OF INTEREST}

None declared.

\section{REFERENCES}

1. Inagaki T, Rha KH, Ong AM, Kavoussi LR, Jarrett TW: Laparoscopic pyeloplasty: current status. BJU Int. 2005; 95(Suppl 2): 102-5.

2. Persky L, Krause JR, Boltuch RL: Initial complications and late results in dismembered pyeloplasty. J Urol. 1977; 118: 162-5.

3. Motola JA, Badlani GH, Smith AD: Results of 212 consecutive endopyelotomies: an 8-year followup. J Urol. 1993; 149: 453-6.

4. Nadler RB, Rao GS, Pearle MS, Nakada SY, Clayman $\mathrm{RV}$ : Acucise endopyelotomy: assessment of long-term durability. J Urol. 1996; 156: 1094-7; discussion 1097-8.

5. Schuessler WW, Grune MT, Tecuanhuey LV, Preminger GM: Laparoscopic dismembered pyeloplasty. J Urol. 1993; 150: 1795-9.
6. Bauer JJ, Bishoff JT, Moore RG, Chen RN, Iverson AJ, Kavoussi LR: Laparoscopic versus open pyeloplasty: assessment of objective and subjective outcome. J Urol. 1999; 162: 692-5.

7. Brooks JD, Kavoussi LR, Preminger GM, Schuessler WW, Moore RG: Comparison of open and endourologic approaches to the obstructed ureteropelvic junction. Urology. 1995; 46: 791-5.

8. Rodrigues H, Rodrigues P, Ruela M, Bernabé A, Buogo G: Dismembered laparoscopic pyeloplasty with antegrade placement of ureteral stent: simplification of the technique. Int Braz J Urol. 2002; 28: 439-44; discussion 445.

9. Mitre AI, Brito AH, Srougi M: Laparoscopic dismembered pyeloplasty in 47 cases. Clinics (Sao Paulo). 2008; 63: 631-6.

10. Janetschek G, Peschel R, Frauscher F: Laparoscopic pyeloplasty. Urol Clin North Am. 2000; 27: 695-704. Erratum in: Urol Clin North Am. 2001; 28: xi. Franscher F [corrected to Frauscher F].

11. Rassweiler JJ, Seemann O, Frede T, Henkel TO, Alken P: Retroperitoneoscopy: experience with 200 cases. J Urol. 1998; 160: 1265-9.

12. Jarret TW, Fabrizio MD, Lamont DJ: Laparoscopic peloplasty: five-year experience. J Urol. 1999; 161: 24(suppl.), abstract \#79.

13. Soulié M, Salomon L, Patard JJ, Mouly P, Manunta A, Antiphon P, et al.: Plante P: Extraperitoneal laparoscopic pyeloplasty: a multicenter study of 55 procedures. J Urol. 2001; 166: 48-50.

14. Türk IA, Davis JW, Winkelmann B, Deger S, Richter F, Fabrizio MD, et al.: Laparoscopic dismembered pyeloplasty--the method of choice in the presence of an enlarged renal pelvis and crossing vessels. Eur Urol. 2002; 42: 268-75.

15. Sundaram CP, Grubb RL 3rd, Rehman J, Yan Y, Chen C, Landman J, et al.: Laparoscopic pyeloplasty for secondary ureteropelvic junction obstruction. J Urol. 2003; 169: 2037-40.

16. Mandhani A, Kumar D, Kumar A, Kapoor R, Dubey D, Srivastava A, et al.: Safety profile and complications of transperitoneal laparoscopic pyeloplasty: a critical analysis. J Endourol. 2005; 19: 797-802.

17. Moon DA, El-Shazly MA, Chang CM, Gianduzzo TR, Eden CG: Laparoscopic pyeloplasty: evolution of a new gold standard. Urology. 2006; 67: 932-6.

18. Rassweiler JJ, Teber D, Frede T: Complications of laparoscopic pyeloplasty. World J Urol. 2008; 26: 539-47.

19. Brito AH, Mitre AI, Srougi M: Laparoscopic pyeloplasty in secondary obstruction. J Endourol. 2007; 21: 1481-4. 
20. Shoma AM, El Nahas AR, Bazeed MA: Laparoscopic pyeloplasty: a prospective randomized comparison between the transperitoneal approach and retroperitoneoscopy. J Urol. 2007; 178: 2020-4; discussion 2024.

21. Vijayanand D, Hasan T, Rix D, Soomro N: Laparoscopic transperitoneal dismembered pyeloplasty for ureteropelvic junction obstruction. J Endourol. 2006; 20: $1050-3$.

22. Sung GT, Gill IS, Hsu TH: Robotic-assisted laparoscopic pyeloplasty: a pilot study. Urology. 1999; 53: 1099-103.
23. Gettman MT, Peschel R, Neururer R, Bartsch G: A comparison of laparoscopic pyeloplasty performed with the daVinci robotic system versus standard laparoscopic techniques: initial clinical results. Eur Urol. 2002; 42: 453-7; discussion 457-8.

24. Freilich DA, Nguyen HT, Borer J, Nelson C, Passerotti CC: Concurrent management of bilateral ureteropelvic junction obstruction in children using robotic-assisted laparoscopic surgery. Int Braz J Urol. 2008; 34: 198204; discussion 204-5.
Accepted after revision: March 15, 2010

\section{Correspondence address:}

Dr. Marco Túlio Coelho Lasmar

Felício Rocho Hospital

Rua Timbiras, 3642, Salas 701/703

Belo Horizonte, MG, 30140-062, Brazil

E-mail: lasmar.uro@uol.com.br

\section{EDITORIAL COMMENT}

This article reinforces that excellent results of laparoscopic pyeloplasty can be consistently obtained by many authors. In those services with experience in laparoscopy, it is considered the standard of care for relieving all conditions related to pyeloureteral junction obstruction for adults and older children.

The rate of success of Anderson-Hynes dismembered pyeloplasty has duplicated that of open surgery with incomparable less invasiveness. The endopyelotomy (transureteral, percutaneous or by Acucise catheter) showed reduced results when compared to conventional or laparoscopic pyeloplasty and for this reason is nowadays much less used.

Transperitoneal or retroperitoneal access is no longer a concern but much more a preference for surgeons. Laparoscopic pyeloplasty has shown to be an excellent option for secondary pyeloureteral obstruction as considered in discussion. Removal of renal associated stones may depend on intra-renal location, size, number of stones, and the anatomy of the urinary tract and the rate of success is not uniform. Flexible nephroscope may be an important tool to retrieve calyceal stone not approachable using rigid lens, leaving more kidneys stone free.

When available, in my opinion, the assistance of the Da Vinci robot may become laparoscopic pyeloplasty accessible for all urologists particularly those with no experience with laparoscopic procedure.

Dr. Anuar I. Mitre University of Sao Paulo, USP Sao Paulo, Brazil E-mail:anuar@mitre.com.br 